\title{
SACROCOCCYGEAL CHORDOMA DIAGNOSED BY FNAC: A RARE CASE REPORT
}

\author{
Patel Kalpan¹, Jajee Ashwini², Chaudhari Ami ${ }^{3}$, Patel Purvi ${ }^{4}$, Pandya Neha ${ }^{5}$
}

\section{HOW TO CITE THIS ARTICLE:}

Patel Kalpan, Jajee Ashwini, Chaudhari Ami, Patel Purvi, Pandya Neha. "Sacrococcygeal Chordoma Diagnosed by FNAC: A Rare Case Report". Journal of Evolution of Medical and Dental Sciences 2014; Vol. 3, Issue 22, June 02; Page: 6163-6168, DOI: $10.14260 /$ jemds/2014/2718

ABSTRACT: Chordoma is rare, slow growing but locally aggressive neoplasms derived from primitive notochordal elements. It accounts for 1- $4 \%$ of all primary bone tumors and mainly found in the sacrococcygeal and spheno-occipital regions. Preoperative fine needle aspiration cytology (FNAC) examination of the tumor is diagnostic. Treatment is in the form of surgical excision, radiation therapy or a combination of both modalities. FNAC improves prognosis and survival rate due to early diagnosis.

KEYWORDS: Chordoma, Sacrococcygeal, FNAC, Physaliphorous, Notochord.

INTRODUCTION: Chordoma is rare, slow growing, but locally aggressive neoplasms derived from primitive notochordal elements. ${ }^{1}$ It was first described by Virchow in 1857 under the name of "ecchordosis physaliphora" and in 1894, Ribbert defined as a malignant tumor arising from embryonic remains of the notochord. ${ }^{2}$ It accounts for $1-4 \%$ of all primary bone tumors ${ }^{3}$ and mainly found in the sacrococcygeal and spheno-occipital regions. Sacrococcygeal tumor more common in fifth and sixth decade whereas in speno-occipital in children and adolescent. ${ }^{4}$

On microscopy, the tumor shows varied but characteristic morphological features and preoperative fine needle aspiration cytology (FNAC) examination of the tumor is diagnostic. ${ }^{5}$ They have little metastatic potential, but considerable local destructiveness. ${ }^{6}$ Treatment is in the form of surgical excision, radiation therapy or a combination of both modalities. ${ }^{4}$

Very few case reports are available of preoperative cytological diagnosis of chordoma. We recently came across an unusual case of sacral mass, where fine needle aspiration cytology along with immunocytochemistry and radiological findings clinched the diagnosis of sacrococcygeal chordoma.

CASE REPORT: A 26 years old male was admitted with complain of swelling at sacro-coccygeal area in surgical ward, SMIMER Hospital, Surat. On examination, approx 16x16 cm single swelling with soft and hard areas was identified on sacrococcygeal region. Per-rectal examination detected a soft cystic mass in presacral region about five centimeters in diameter, pushing the posterior rectal wall anteriorly.

Motor and sensory functions of both lower limbs and anal reflexes were normal. Routine investigations were within normal limits. So on, provisional clinical diagnosis was Sacrococcygeal Teratoma. On USG, it showed large heterogenous solid mass lesion with internal vascularity noted posterior to urinary bladder.

On CT Scan, Approx 19.3(AP) x 16.4(Trans) x 17.4 (SI) cm sized well defined, expansile lytic lesion with heterogenous enhancement and multiple splotchy calcification within it, seen arising from sacrum \& coccyx extending from level of L5-S1 superiorly to inferior half of coccyx inferiorly. Marked destruction of underlying related bones along with compressive anterior displacement of abdominal 
visceras, gave diagnosis of likely malignant sacral mass, possibility of Sacro-coccygeal chordoma was more likely than Giant cell tumor. Patient was referred to cytopathology department, SMIMER Hospital for Fine needle aspiration cytology.

FNAC was performed at three different sites at a time on lesion, yielded blood stained material. On microscopy, smears were cellular comprising of round to pleomorphic cells arranged in clusters, monolayered sheet and scattered singly and classic mono and bi nucleated physaliphorous cells. Nucleus showed moderate anisokaryosis, granular chromatin \& was centrally located with prominent nucleoli and intranuclear inclusion.

Tumor cells are encircled with abundant fibrillary chondromyxoid ground substance in hemorrhagic background. On immunocytochemistry, cells showed positivity for pankeratin, S-100, vimentin and EMA. Above cytological features and immunocytochemistry confirmed the diagnosis of CHORDOMA.

DISCUSSION: Chordoma is a low to intermediate grade malignant tumor that recapitulates notochord. ${ }^{3}$ This is confirmed by the recent evidence that brachyury, a transcription factor involved in notochordal development, is detectable in the disease. ${ }^{7}$ Chordoma is a slow-growing neoplasm with little metastatic, but considerable local destructive potential, typically occurring in the axial skeleton at either ends of the spinal column.

About 50\% arise in the sacrococcygeal area, 35\% in the spheno-occipital area and the remainder along the cervico-thoraco-lumbar spine. ${ }^{4}$ In rare cases, chordoma has been reported in non-axial sites of the skeleton or within the soft tissue without bone involvement. ${ }^{8}$ In keeping with the diffuse viewpoint that this tumor arises from notochordal remnants, the complex phenotype of chordoma, which includes both epithelial and mesenchymal characteristics, has been regarded to recapitulate the vertebral differentiation pathway at the notochord-to-nucleus pulposus transition stage of development. ${ }^{9}$

Recent studies suggest that rare genetic or hereditary factors may increase the risk of relatives developing chordomas in some families, which has been concluded by National cancer Institute, Genetic Epidemiology Branch.10 It is commonly present after the age of thirty, the sacrococcygeal tumors are more common in the fifth and sixth decades of life, but distinctly uncommon in patients younger than twenty years of age, the tumors in this age group tend to occur in the base of the skull and the cervical spine.

The clinical presentation is entirely dependent on the location of the chordoma. At the sacrum, common presenting symptoms are back and/or lower extremity pain. About one half of patients with chordomas have autonomic symptoms, particularly rectal dysfunction or urinary incontinence. About one half of patients with chordomas have a palpable sacral mass. ${ }^{7}$

On gross, ${ }^{4}$ it is gelatinous and soft with areas of hemorrhage.

On histopathology, 4 It resembles the normal notochordal tissue in different stages of development. It grows in cords and lobules separated by variable but usually extensive amount of mucoid intercellular tissue. Some of the tumor cells (physaliphorous) are extremely large, with vacuolated cytoplasm and prominent vesicular nuclei. Other tumor cells are small with no visible nucleoli. Mitotic figure are generally scant or absent.

On cytopathology,11 it shows large, mono and binucleated physaliphorous cells with vacuolated cytoplasm, centrally located nuclei, having granular chromatin pattern and small nucleoli 
along with presence of small round uniform cells and short spindle shaped cells and metachromatic stained chondromyxoid ground substance which surrounds individual cell. Cells occasionally look like signet ring cell with large cytoplasmic vacuole pushing the nucleus to periphery. Cartilaginous stroma present in chondroid variant.

On immunochemistry ${ }^{4}$, it should be positive for $\mathrm{S}-100$, keratin, EMA, HMBE - 1, cathepsin K and $\mathrm{E}$ - cadherin.

Microscopic differential diagnosis includes chondrosarcoma, signet ring adenocarcinoma of rectum, osteosarcoma, myxopapillary ependymoma. The close differential diagnosis on cytology chondrosarcoma can be differentiated by pattern of chondromyxoid substance and immunocytochemistry.

According to the Chordoma Foundation ${ }^{12}$, Surgery is the mainstay of treatment for chordomas. The goal of surgery is to remove as much of the tumor as possible without causing unacceptable harm. For some patients, radiation therapy and proton beam therapy can reduce the risk of recurrence after surgery and prolong survival. For patients who are not candidates for surgery, radiation therapy is sometimes used as the primary treatment.

There are currently no drugs approved by the FDA to treat chordoma. The median overall survival for chordoma patients in the United States is approximately 9 years, and the overall 5, 10 and 20 year survival rates are 68\%, 40\% and 13\%, respectively. Prognosis for each person is different depending on age, size and location of the tumor, histological subtype, method of treatment, extent of resection, and other factors.

CONCLUSION: Chordoma is a rarely encountered, slowly growing malignant tumor of fetal notochord origin. FNAC is a safe, simple, quick and minimally invasive method of pre- operative diagnosis because of the distinct cytological features and improve prognosis and survival rate due to early diagnosis.

\section{REFERENCES:}

1. S. Rao BS, Menezes LT, Rao AD, John SK. Sacral chordoma - a report of two cases. Indian Journal of Surgery. 2005; 67(4): 207-209.

2. Lopes A, Rossi BM, Silveira CR, Alves AC. Chordoma: retrospective analysis of 24 cases. Sao Paulo Med. J. Nov. /Dec. 1996; 114 (6): 1312-6.

3. Mirra JM, Nelson SD, Rocca CD, Mertens F. Chordoma. World Health Organization Classification of Tumours. Pathology and Genetics of Tumours of Soft Tissue and Bone. Lyon: IARC Press; 2002. p 316-7.

4. Rosai J. Rosai and Ackerman's Surgical Pathology, 10th ed, India: Elsevier Inc.; 2012.p 2055-7.

5. Crapanzano JP, Ali SZ, Ginsberg MS, Zakowski MF. Chordomaa cytologic study with histologic and radiologic correlation. Cancer Cytopathology. 2001; 93: 40-51.

6. Sabuncuog H, Ozdogan S, Dogan H, Ataoglu O, Timurkaynak E. Total Resection of Inferiorly Located Sacral Chordoma with Posterior Only Approach: Case Report and Review of the Literature. Turkish Neurosurgery. 2010; 20(4): 527-32.

7. Sigdel B, Baidya R. Chordoma: study of five cases. Journal of Pathology of Nepal. 2012; 2: 260 -4.

8. Nielsen GP, Mangham DC, Grimer RJ, Rosenberg AE. Chordoma periphericum: A case report. Am J Surg Pathol. 2001; 25: 263-7. 


\section{CASE REPORT}

9. Gottschalk D, Fehn M, Patt S, Saeger W, Kirchner T, Aigner T. Matrix gene expression and cellular phenotyping in chordoma reveals focal differentiation pattern of neoplastic cells mimicking nucleus pulposus development. Am J Pathol. 2001; 158: 1571-8.

10. Chordoma Study, division of cancer epidemiology and genetics, genetic epidemiology branch, National Cancer Institute; Available at http://dceg.cancer.gov/research/clinicalstudies/chordoma. Accessed on May 4th, 2014.

11. Lin 0, Zakowski MF. Comprehensive cytopathology (Bibbo), 3 $3^{\text {rd }}$ Edition. China: Elsevier Inc; 2008. p 499-501.

12. Chordoma Foundation. Available at: http://www.chordomafoundation.org. Accessed on May $4^{\text {th }}, 2014$.

Figure 1: 16x16 cm single swelling with soft and hard areas on sacro-coccygeal region/buttock region.

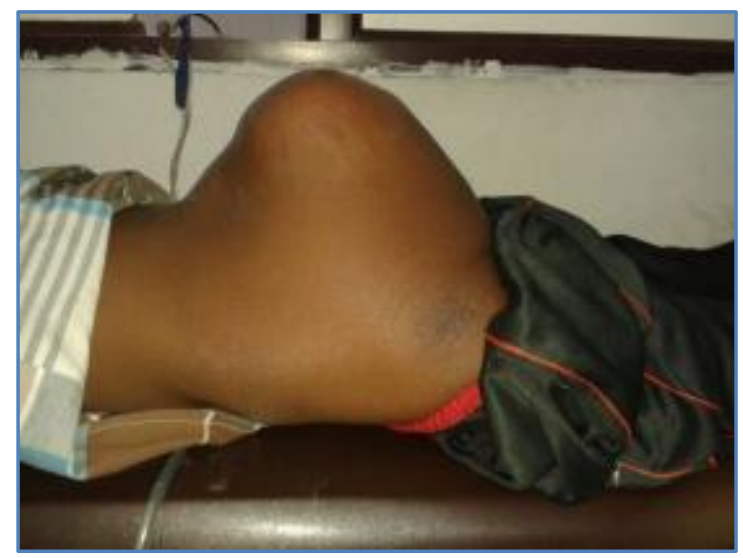

\section{Figure 1}

Figure 2: CT Scan shows well defined, expansile lytic lesion with heterogenous enhancement and multiple splotchy calcification within it is seen arising from sacrum \& coccyx.

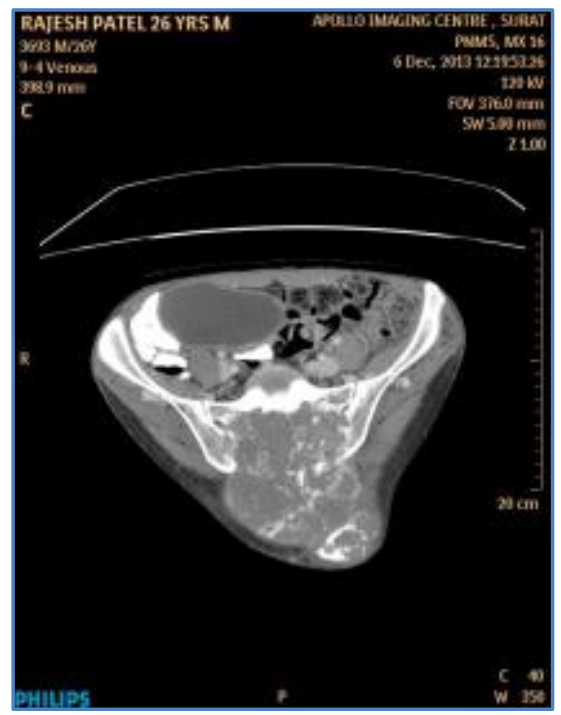

Figure 2 


\section{CASE REPORT}

Figure 3: (PAP stain, $40 \mathrm{X}$ ) Large mono and bi nucleated PHYSALIPHOROUS CELLS (cells with vacuolated/bubbly cytoplasm)

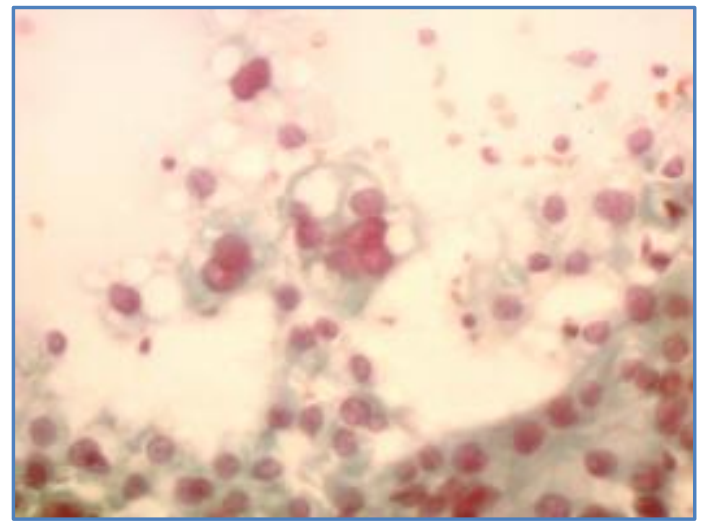

\section{Figure 3}

Figure 4: (Giemsa stain, $40 \mathrm{X}$ ) Tumor cells are encircled with abundant fibrillary chondromyxoid ground substance (metachromatic on Giemsa)

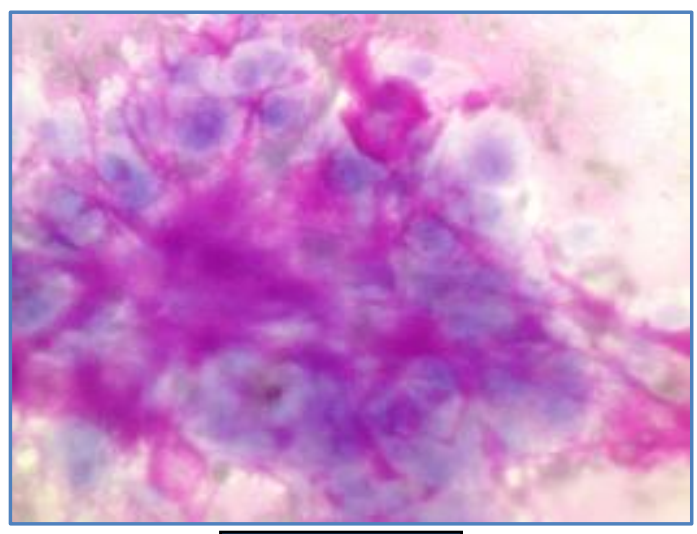

\section{Figure 4}

Figure 5: ICC Pankeratin - positive.

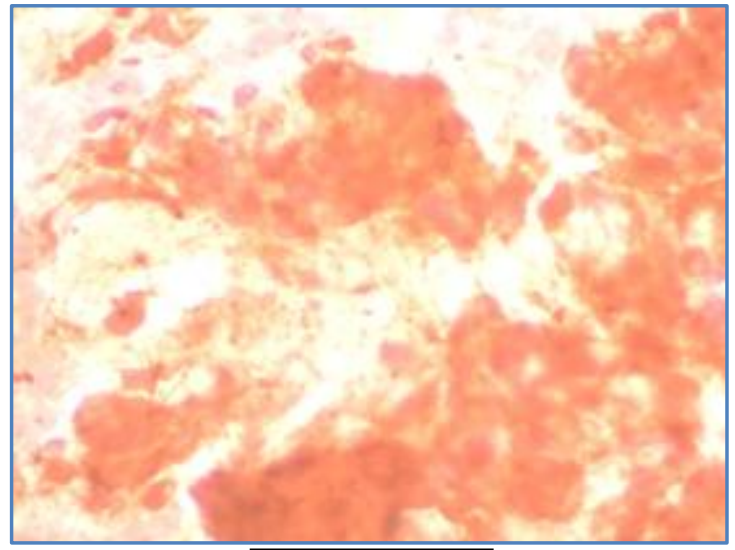

\section{Figure 5}




\section{CASE REPORT}

Figure 6: ICC S-100 - positive.

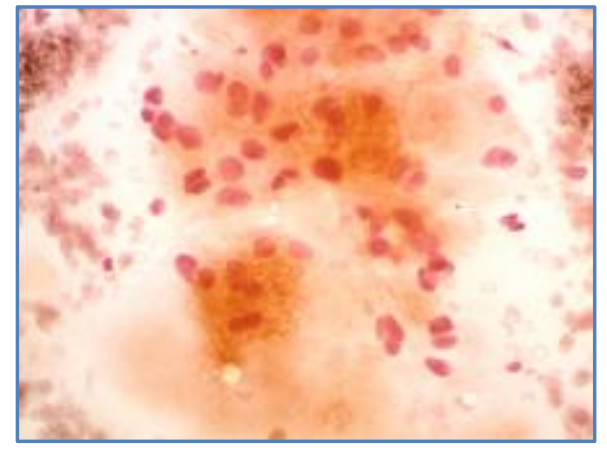

\section{Figure 6}

Figure 7: ICC Vimentin - positive.

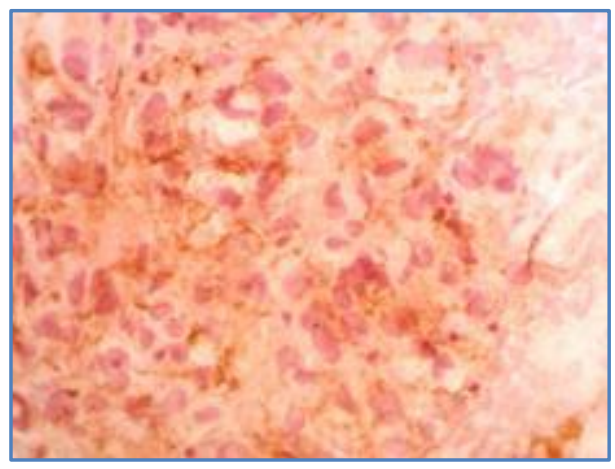

Figure 7

\section{AUTHORS:}

1. Patel Kalpan

2. Jajee Ashwini

3. Chaudhari Ami

4. Patel Purvi

5. Pandya Neha

\section{PARTICULARS OF CONTRIBUTORS:}

1. II ${ }^{\text {nd }}$ Year Resident, Department of Pathology, SMIMER Hospital, Surat, Gujarat.

2. Associate Professor, Department of Pathology, SMIMER Hospital, Surat, Gujarat.

3. Assistant Professor, Department of Pathology, SMIMER Hospital, Surat, Gujarat.

4. Tutor, Department of Pathology, SMIMER Hospital, Surat, Gujarat.

5. Tutor, Department of Pathology, SMIMER Hospital, Surat, Gujarat.

\section{NAME ADDRESS EMAIL ID OF THE} CORRESPONDING AUTHOR:

Dr. Ashwini B. Jajee,

No. 5, Vidya Vihar Soc,

Near Jamna Nagar Soc,

Ghod Dod Road, Surat-395001,

Gujarat.

Email: ashushukla73@yahoo.co.in

Date of Submission: 12/05/2014.

Date of Peer Review: 13/05/2014.

Date of Acceptance: 21/05/2014.

Date of Publishing: 31/05/2014. 